\title{
Evaluating Low-Cost Commercially Available Sensors for Air Quality Monitoring and Application of Sensor Calibration Methods for Improving Accuracy
}

\author{
Nam H. Nguyen*, Huy X. Nguyen, Thuan T. B. Le, Chinh D. Vu \\ Medical Equipment Research Center, Viettel High Technology Industries Corporation, Hanoi, Vietnam \\ Email: *namnh74@viettel.com.vn
}

How to cite this paper: Nguyen, N.H., Nguyen, H.X., Le, T.T.B. and Vu, C.D. (2021) Evaluating Low-Cost Commercially Available Sensors for Air Quality Monitoring and Application of Sensor Calibration Methods for Improving Accuracy. Open Journal of Air Pollution, 10, 1-17. https://doi.org/10.4236/ojap.2021.101001

Received: December 21, 2020

Accepted: March 20, 2021

Published: March 23, 2021

Copyright $\odot 2021$ by author(s) and Scientific Research Publishing Inc. This work is licensed under the Creative Commons Attribution International License (CC BY 4.0).

http://creativecommons.org/licenses/by/4.0/

\begin{abstract}
In this paper, we present the results of the evaluation of three low-cost laser sensors and comparison with the standard device Metone Aerocet 531s which is capable of counting dust particles as small as $0.3 \mu \mathrm{m}$. The sensors used in this study are PMS5003 (Plantower), SPS30 (Sesirion), SM-UART-04L (Amphenol). During the measurement, the overall trend of the outputs from the sensors was similar to that of the Aerocet 531s. The PMS5003 sensor has a relatively small standard error in the all particle measurement ranges $(<15$ $\mu \mathrm{g} / \mathrm{m}^{3}$ in the low particle concentration range). All sensors have a high linearity compared to data from standard equipment, PMS5003: PM1.0 $\mathrm{R}^{2}=0.89$; PM2.5 R $\mathrm{R}^{2}=0.95$; PM10 R $\mathrm{R}^{2}=0.87$; SPS30 PM2.5 $\mathrm{R}^{2}=0.95$ and PM10 $\mathrm{R}^{2}=$ 0.99; SM-UART-04L PM1.0 $\mathrm{R}^{2}=0.98$. Three main sensor calibration methods (single-point calibration, two-point calibration and multi-point curve correction) with implementation steps for each method as well as their practical applications in calibrating low-cost air quality sensors according to standard measuring equipment are also detailed illustrated.
\end{abstract}

\section{Keywords}

Air Quality Sensors, Sensor Calibration, Air Pollution, Fine Particle, Laser Particle Sensor, PM1.0, PM2.5, PM10

\section{Introduction}

Air pollution levels are dangerously high in many parts of the world. New data from WHO in 2018 shows that nine out of ten people worldwide are breathing polluted air [1] [2]. 
Air pollution has many harmful effects on human health. Sensitive people can suffer even during days with low air pollution level. Short-term exposure to air pollutants is firmly linked to COPD (Chronic Obstructive Pulmonary Disease), cough, breathing difficulty, asthma, and respiratory problems [3] [4] [5] [6].

The long-term effects associated with air pollution are chronic asthma, lung failure, cardiovascular diseases (myocardial infarction, cardiac arrhythmias, and ischemic stroke) and cardiovascular-related death. In addition, air pollution has many negative health effects in early pregnancy, such as respiratory and cardiovascular disorders that lead to infant mortality or chronic illness in adulthood [3] [4].

Particulate matter is a complex mixture of inorganic and organic particles in the liquid or solid form suspended in the air. Particulate matter is designated according to their aerodynamic diameter, meaning particulate with diameter of $\mathrm{x} \mu \mathrm{m}$ or less is called PMx (some common names are PM1.0, PM2.5 and PM10). Fine (diameter $<2.5 \mu \mathrm{m}$ ) and ultrafine (diameter $<0.1 \mu \mathrm{m}$ ) dust particles can be generated from nature such as: forest fires, desert dust, volcanic smoke, sandstorms, cyclones or from pollen, fungal spores, insect wastewater or is generated from human activities through burning charcoal, burning garbage, smoking, smoke from industrial zones, construction works, vehicles.

In addition to particulate matter, gaseous pollutants also pose a serious threat to human health in recent years. Gases such as $\mathrm{CO}, \mathrm{SO}_{2}, \mathrm{NO}$, TVOC are byproducts of fossil fuel combustion from transportation and industrial plants which affect the respiratory system (breathing difficulty, cause headache, thrombosis, cardiovascular diseases (arrhythmia, heart failure) [7].

According to a study by the World Health Organization and the International Agency for Research on Cancer IARC, there is a direct correlation between the level of particulate pollution and the incidence of cancer. More specifically, an increase of $10 \mu \mathrm{g} / \mathrm{m}^{3}$ in PM10 concentration in the air means that the incidence of cancer would increase by $22 \%$. As PM2.5 concentration increases by $10 \mu \mathrm{g} / \mathrm{m}^{3}$, the incidence of lung cancer increases by $36 \%$ [8].

PM2.5 and PM10 both enter the airways when inhaled, but penetration depth differs depending on particle size. Coarse particulate like PM10 when enters the body can cause irritation to the eyes, nose, and throat, but will not likely reach the lungs, while fine particulate like PM2.5 is more dangerous because they can penetrate through the respiratory tract deep into the lungs, veins and even enters the blood circulatory system [8] [9]. At everyday level of exposure, these fine particulate can cause healthy people to have a stuffy nose, sore throat, and bronchitis. Though when accumulated for a long period of time, they will increase the risk of disease in the respiratory system, cardiovascular system, circulatory system and human reproductive system [10] [11].

Have such extremely dangerous effects on human health, these particulates are also too small to be detected by naked eye. This leads to the needs to monitor the concentration of fine particulate in both outdoor and indoor air.

Currently, information on air quality at environmental monitoring stations 
provided by governmental and non-governmental organizations can be monitored from websites or mobile applications. The Environmental Protection Agency (EPA) has defined Federal Reference Method (FRM) and Federal Equivalent Method (FEM) which provide standards (functional and performance requirements) for manufacturers to produce an instrument that meets the agency requirements [12] [13]. Measurement tools at these monitoring stations either use FRM devices such as RAAS 2.5 - 300, Andersen Instruments, Sierra-Andersen, 1200, Wedding \& Associates Critical Flow High-Volume Sampler [13] [14] or FEM devices such as $\beta$ attenuation monitors (BAMs) like Andersen Instruments Model FH621-N and Tapered Element Oscillating Microbalance (TEOMs) like Rupprecht \& Patashnik TEOM 1400 [15] which are capable of measuring particulate concentration changes continuously and simultaneously [16]. These standard devices provide high accurate and precise measurement, with standard deviation is within $2 \%-6 \%$ [15]. However, these monitoring stations are expensive and often quite large, makes them less portable and ideal for the individuals to monitor the air quality around the living environment.

Over the past decades, a variety of sensor technologies have emerged, creating a revolutionary change in monitoring and evaluation of air pollution. Sensors which are hundreds of times cheaper than standard measuring devices have opened up many practical applications. In particular, it has become possible to participate more widely in discussions about air quality and use information about air pollution by general public.

The introduction of low-cost sensor technologies critically contributes to solving the increased demand of the general public in monitoring the air quality of the living and working environment. An example is the NDIR (non-scattered infrared) sensor technology that measures $\mathrm{CO}_{2}$. The breakthrough in IR (infrared) source technology as well as sensor design significantly reduces the size of the NDIR sensor measuring $\mathrm{CO}_{2}$, making it portable and affordable.

With advancement in sensor technology, laser particulate sensors are developed and commercialized with compact size, inexpensive, low energy consumption (5 V and below $250 \mathrm{~mA}$ ) and capable of continuous measurement [17] [18] [19]. For these reasons, they are widely used in automated air quality monitoring systems and IoT devices.

The downside of cheap sensors is the low accuracy when compared to standard measuring devices, which leads to the needs for sensor evaluation and calibration to ensure measurement results. The accuracy of handheld devices equipped with these types of sensors can range from $15 \%$ to over $30 \%$ [20].

Moreover, laser sensors have a big drawback in that the amount of scattered light project depends on the particle parameters: size, shape, density and refractive index. In other words, the values obtained for a fine particulate matter (PM1.0; PM2.5; PM10) may not be accurate for the environment being measured. Therefore, the particulate sensor should be calibrated using data from more highly recognized equipment such as those that meet the EN12341 or EN 16450 standards. 
In this paper we present the results of comparing three low-cost laser particulate sensors with the Metone Aerocet 531s four-channel particle counter. The Aerocet 531s has the ability to detect particles down to $0.3 \mu \mathrm{m}$ in size and measure the effective concentration of particles of sizes PM10, PM2.5 and PM1.0.

\section{Materials and Methods}

\subsection{Materials and Equipment}

Measurements were performed at the testing room inside the lab of Medical Equipment Research Center-Viettel High Technology Industries Corporation. The test chamber is an ISO 5 [21] clean room, equipped with air cleaner, particulate generator capable of generating fine particulate environment under different conditions for testing.

Aeroset 531s is a particle counting device made by Met One, using laser light scattering technology with high accuracy and sensitivity (according to the manufacturer, the device has the accuracy of $\pm 10 \%$ to calibration aerosol). Met One Instruments, Inc. is a company specializes in production of environmental monitoring equipment to meet requirements for government and industry. The equipment has been evaluated and certified by TUB SUV, EPA, and CEP.

The fine particulate sensors on the market selected for this study were PMS5003 (Beijing Plantower Co. Ltd., China), SPS30 (Sensirion, Switzerland), SM-UART-04L (Amphenol Corporation, USA). These sensors were chosen due to being widely used in many air purifiers, air quality monitoring devices as well as their reliability and low-cost. Summary of specifications of the sensors is shown in Table 1.

These sensors are mainly chosen for their cheap price, compact size, and popularity. The PMS5003, SPS30, SM-UART-04L sensors all use light scattering principles to measure and estimate particulate concentration in the air. Light from the laser beam in the measurement chamber is scattered by particles suspended in the air, and the scattered light signal is captured. Then, the equivalent particulate diameter and the number of particles of different diameters could be calculated [17] [18]. Figure 1 illustrates how low-cost laser sensors work.

\subsection{Methods}

The sensors PMS5003, SPS30, SM-UART-04L and the Aeroset 531s device were set next to each other at the center of the cleanroom at $1 \mathrm{~m}$ height from the floor. Each sensor was set at $10 \mathrm{~cm}$ apart to ensure no disturbance of air circulation and homogeneous distribution of particulate matter. The compact size $(15.9 \times$ $10.2 \times 5.4 \mathrm{~cm}$ ) and position away from sensors' inlet warranted no affection on the dynamics of particulates. The cleanroom with the size of $5 \times 2.4 \times 2.25 \mathrm{~m}$, was equipped with one mixing fan and cigarette smoke generator.

The smoke generators created an environment with particulate concentrations of over $1000 \mu \mathrm{g} / \mathrm{m}^{3}$ (PM2.5) to cover the entire measuring range of the sensors to be evaluated. Particulate concentration at the beginning was above $1000 \mu \mathrm{g} / \mathrm{m}^{3}$, 

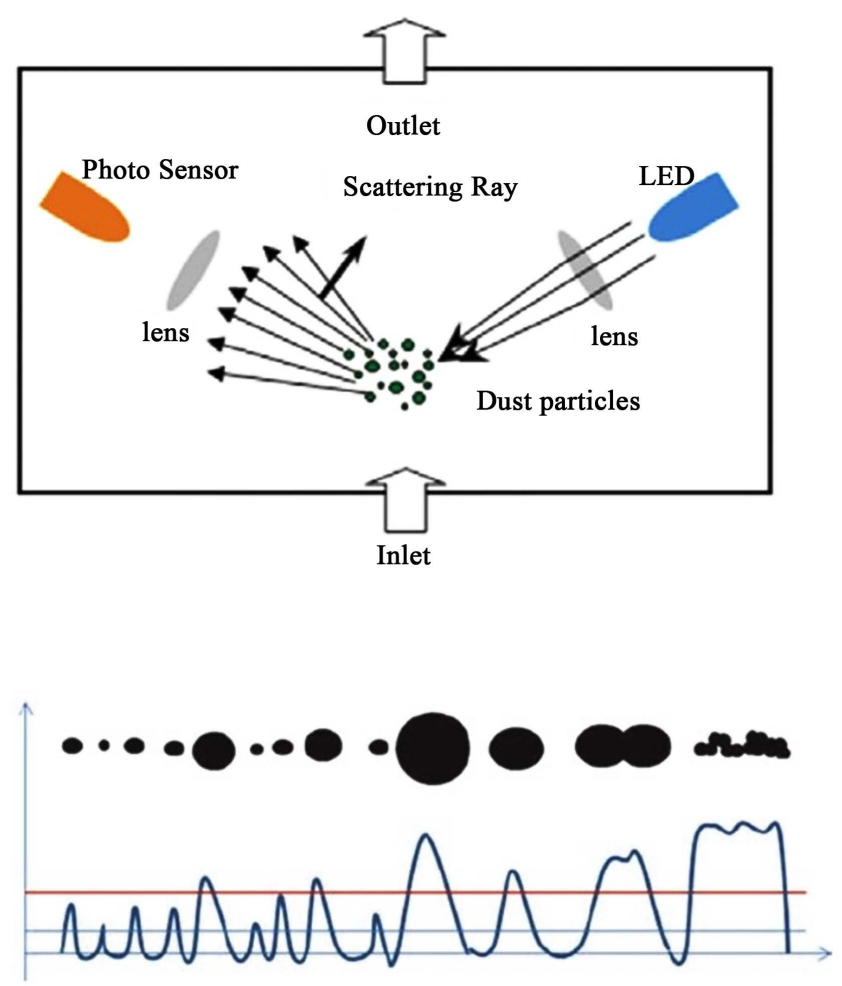

Figure 1. Working principle of laser particulate sensor. After the laser scattering through the particles, the pulse signal outputted by the sensor will be transformed into digital signals. The number and diameter of particles then are obtained by analysis based on the correlation between the signal waveform and the particles diameter.

Table 1. Specifications of the sensors.

\begin{tabular}{|c|c|c|c|c|}
\hline Model & PMS5003 & SPS30 & SM-UART-04L & Aerocet 531s \\
\hline Manufacture & Plantower & SPS30 & Amphenol & Met One \\
\hline $\begin{array}{c}\text { Price }(\$) \\
(\text { MOQ 1000) }\end{array}$ & 13 & 27 & 18 & 3150 \\
\hline $\begin{array}{c}\text { Physical size } \\
(\mathrm{L} \times \mathrm{W} \times \mathrm{H}-\mathrm{mm})\end{array}$ & $50 \times 38 \times 21$ & $40.8 \times 41.2 \times 12.3$ & $48 \times 37 \times 12$ & $159 \times 102 \times 54$ \\
\hline Weight (g) & 42 & 26.3 & 28 & 910 \\
\hline DC Power Supply (V) & $4.5-5.5$ & $4.5-5.5$ & $4.8-5.2$ & \\
\hline Active current (mA) & $\leq 100$ & $45-65$ & $60-100$ & 200 \\
\hline $\begin{array}{l}\text { Particle Range of } \\
\text { measurement }(\mu \mathrm{m})\end{array}$ & $0.3-10.0$ & $0.3-10.0$ & $0.3-10.0$ & $0.3-10.0$ \\
\hline $\begin{array}{l}\text { Particle Type of } \\
\text { measurement }\end{array}$ & $\begin{array}{l}\text { PM1; PM2.5; } \\
\text { PM10; }\end{array}$ & $\begin{array}{c}\text { PM1; PM2.5; } \\
\text { PM10; }\end{array}$ & $\begin{array}{l}\text { PM1; PM2.5; } \\
\text { PM10; }\end{array}$ & $\begin{array}{c}\text { PM1; PM2.5; } \\
\text { PM4; PM7; PM10; }\end{array}$ \\
\hline $\begin{array}{l}\text { Particle Counting } \\
\text { Range }\left(\mu \mathrm{g} / \mathrm{m}^{3}\right)\end{array}$ & $\begin{array}{l}\text { Effective Range: } \\
0 \text { - } 500 \\
\text { Maximum Range: } \\
>1000\end{array}$ & $0-1000$ & $1-999$ & $0-10,000$ \\
\hline Lifespan & MTTF $\geq 3$ years & $>10$ years & $40.000 \mathrm{~h}$ & \\
\hline Accuracy & & & & $\pm 10 \%$ \\
\hline
\end{tabular}


then gradually reduced by using an air purifier to slowly decrease the particulate concentration over time.

The particulate concentration values from the sensors and Aerocet 531s device were recorded synchronously in a 60 second-cycle.

Data collected from the sensors were analyzed, calculated and evaluated with regarding to values from the standard equipment.

\subsubsection{Data Analysis}

Data collected from sensors was analyzed according to three criteria: sensor accuracy, sensor precision and linear relationship of sensor data with the standard measuring equipment.

\section{a) Sensor accuracy}

Sensor accuracy was assessed based on statistical analysis of deviation data compared to data from the standard measuring device. This directly affected the quality assessment for each sensor as well as the sensor data calibration process. For the highest accuracy data and data drift correction if necessary, the measuring instrument should be calibrated prior and after field test.

\section{b) Sensor precision}

The precision of the sensor represents the stability and variability of the data from the sensor. The higher the precision sensor, the more concentrated the data; the smaller the difference between the data from the sensors, the easier it will be to calibrate the sensor to bring the sensor value back to the correct value, especially in case of calibration for a batch of sensors from the same model.

c) Linear relationship of sensor data.

The linear relationship of data between the laser particulate sensor and the measuring device is assessed through the Coefficient of Determination $\mathrm{R}^{2}$ between the sensor and the standard measuring device according to different particulate concentration ranges: $0-100 \mu \mathrm{g} / \mathrm{m}^{3} ; 100-500 \mu \mathrm{g} / \mathrm{m}^{3} ; 500-1000 \mu \mathrm{g} / \mathrm{m}^{3}$. A high $\mathrm{R}^{2}$ value means a strong linear relationship between the two datasets, which would lead to a simple linear regression model (as opposed to complex nonlinear ones) of sensor calibration.

\subsubsection{Sensor Calibration}

With the expense of only $3-100$ USD per sensor, the cost of the air quality monitoring equipment has decreased significantly from thousands and tens of thousands of dollars to 50 - 1000 USD [22] [23]. The downside of these low-cost sensor technologies is that their accuracy is relatively low compared to standard measuring equipment. The cheaper the sensor is, the less sensitivity and specificity are. Reasons for the decline in accuracy include material quality used as sensors, technology used (indirect measurement $-\mathrm{CO}_{2}$ sensor, TVOC). Therefore, in order to use these low-cost sensor technologies effectively, sensor calibration is often required.

In addition, sensors are essentially electronic devices, therefore they are very sensitive to changes in the working environment. Unexpected and sudden changes in the sensor's working environment (high temperature, high humidity, degra- 
dation, external shocks) will result in faulty output values [24]. The process of comparing between the real output value and the measured output value is called sensor calibration. Sensor calibration plays an important role in increasing sensor efficiency by offsetting structural errors caused by sensors.

There are 3 main sensor calibration methods: single-point calibration, two-point calibration and multi-point curve calibration [25] [26]. The calibration methods as well as practical applications to calibrate some sensors will be detailed in the next part.

\section{Terms and definitions}

- Standard reference value: For each type of sensor (particulate or gas), choose a measuring device to be the standard reference value (with PMx particulate is the Met One Aerocet 531s, with $\mathrm{CO}_{2}$ being Testo 315-3).

- Linearity curve: Each sensor will have a characteristic curve, representing the sensor's response value to the input parameter. Calibration maps the sensor's response to an ideal linear response curve. The correction method will depend on the nature of the characteristic curve.

- Offset: The sensor output is higher or lower than the ideal output. Offset is very easy to correct with single point correction.

- Sensitivity or Slope: The slope difference means that the sensor output changes at a different speed than the ideal output. Two-point calibration process can correct differences in slope.

\section{1) Single-point calibration}

Single-point calibration is the simplest type of calibration. Single-point calibration can be used to correct sensor deviation in cases where the tested sensor has a linear characteristic and has an exact slope within the desired measurement range. In this case, it is only necessary to correct one point within the measuring range and adjust the error to the measured value. Single-point calibration can also be used as a "drift check" to detect changes in response and/or deterioration in sensor performance over time.

\section{2) Two-point calibration}

Two-point calibration is more complicated than one-point calibration. Essentially, two-point calibration is capable of correcting both slope and offset errors. The calibration is performed as below:

- Take two measurements with the sensor to be calibrated: One near the lower limit of the measuring range and one near the upper limit of the measuring range. Record these measurements as "RawLow" and "RawHigh".

- Repeat these measurements with the appropriate standard measuring equipment. Record these values as "RefLow" and "RefHigh".

- Calculate "RawRange” by subtracting RawLow from RawHigh.

- Calculate "RefRange" by subtracting RefLow from RefHigh.

- Finally, calculate the corrected value "CorrectedValue" using the formula:

$$
\text { Corrected Value }=\frac{(\text { RawValue }- \text { RawLow })}{\text { RawRange }} \text { RefRange }+ \text { RefLow }
$$




\section{3) Multi-point curve calibration}

Multi-point curve calibration is the most complex method and is used when the sensor response is not linear within the range. This method often requires curvature correction to calibrate for the nonlinearity of the response. This method is usually performed by taking measurements for many of the reference correction points within the measuring range.

With a sufficiently large set of measured values, curvature coefficients for the sensor's characteristic curve can be calculated. These coefficients are used to construct a linearization formula to compensate for errors in sensor measurements.

\section{Results and Discussion}

\section{1) Evaluate the sensor accuracy}

Figure 2 shows the results of sensor accuracy assessment, evaluating the particulate concentration of PM1.0, PM2.5 and PM10 data obtained from three sensor models. It could be clearly seen, the higher the particulate concentration, the greater the error between the sensor and the standard measuring device.

Sensor errors compared to the Aerocet 531s were evaluated at different measuring ranges for each particulate size. The sensor error assessment results are shown in Table 2. In general, the PMS5003 sensor has better accuracy than the other 2 sensors (below $15 \mu \mathrm{g} / \mathrm{m}^{3}$ or $15 \%$ in the particulate sizes PM2.5 and PM10). In case of particulate size PM1.0, all sensors have quite a large error range, especially up to over $230 \%$ for SM-UART-04L sensor.

\section{2) Evaluate the sensor precision}

Sensor precision was assessed by the standard deviation between sensors of the same type.

Table 2. Errors of the sensors in different measurement ranges compared to standard device.

\begin{tabular}{ccccccc}
\hline & $\begin{array}{c}\text { Measurement range } \\
\left(\mu \mathrm{g} / \mathrm{m}^{3}\right)\end{array}$ & $0-25$ & $25-50$ & $50-100$ & $100-200$ & \\
PM1.0 & PMS5003 & $32.7 \%$ & $10.4 \%$ & $62.0 \%$ & $126.7 \%$ & \\
& SPS30 & $45.4 \%$ & $26.1 \%$ & $101.9 \%$ & $48.7 \%$ & SD (\%) \\
& SM-UART-04L & $113.9 \%$ & $47.2 \%$ & $233.7 \%$ & $232.4 \%$ & \\
\hline \multirow{4}{*}{ PM2.5 } & Measurement range & $0-50$ & $50-200$ & $200-500$ & $500-1000$ & \\
& $\left(\mu \mathrm{g} / \mathrm{m}^{3}\right)$ & & & & & \\
& PMS5003 & $11 \%$ & $10.4 \%$ & $14.6 \%$ & $25.7 \%$ & \\
& SPS30 & $2.7 \%$ & $26.1 \%$ & $16.6 \%$ & $16.6 \%$ & SD (\%) \\
& SM-UART-04L & $24.7 \%$ & $47.2 \%$ & $26.5 \%$ & $12.3 \%$ & \\
\hline \multirow{2}{*}{ PM10 } & Measurement range & $0-50$ & $50-100$ & $100-250$ & $250-1000$ & \\
& $\left(\mu \mathrm{g} / \mathrm{m}^{3}\right)$ & & & & & \\
& PMS5003 & $11.3 \%$ & $7.6 \%$ & $10.9 \%$ & $18.9 \%$ & \\
& SPS30 & $11.4 \%$ & $11.4 \%$ & $22.1 \%$ & $25.9 \%$ & SD (\%) \\
& SM-UART-04L & $17.0 \%$ & $17.0 \%$ & $19.9 \%$ & $8.4 \%$ & \\
\hline
\end{tabular}

* SD—standard deviation of measured value by sensor compared to standard device. 
PM1.0
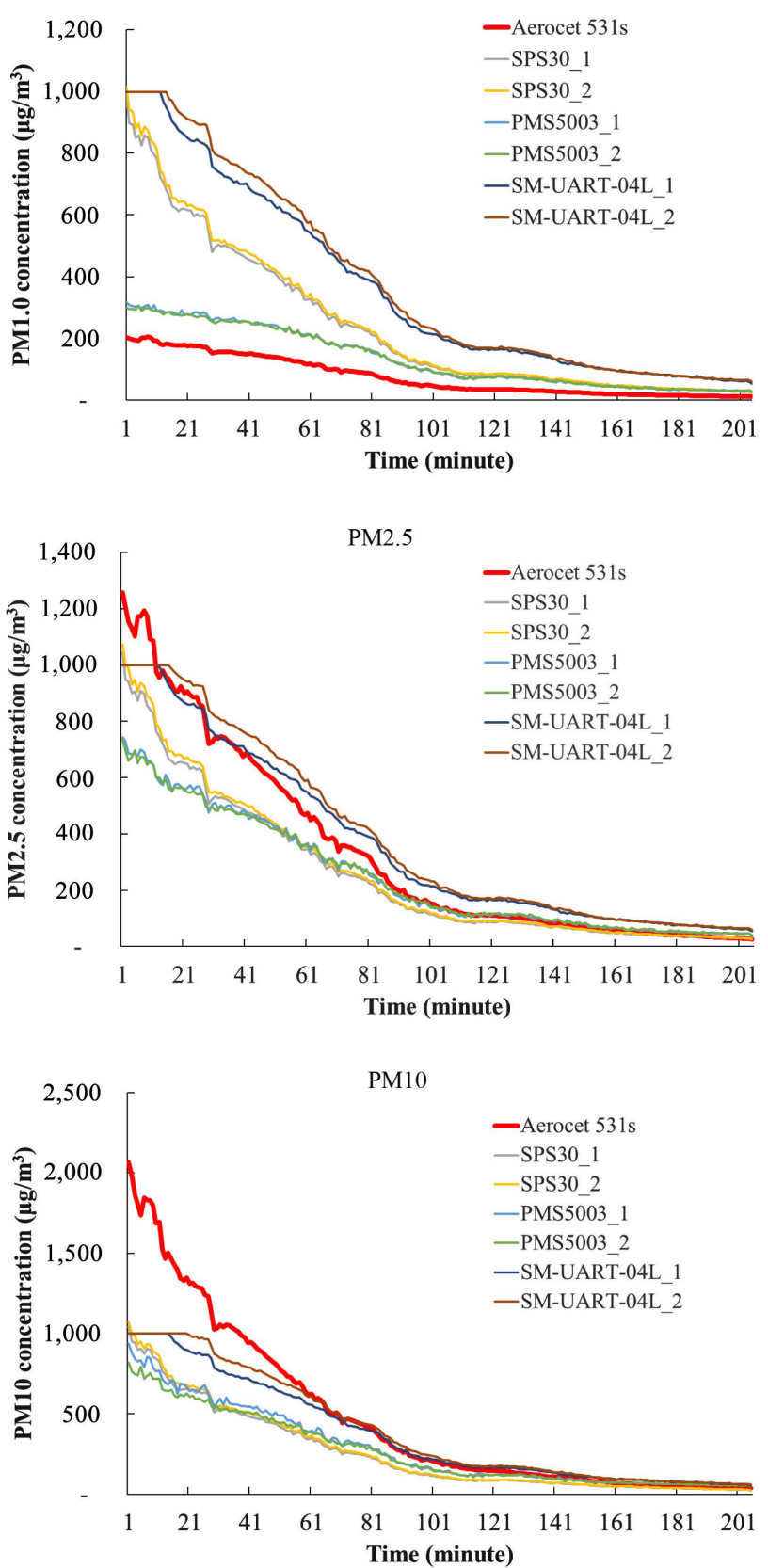

Figure 2. The results of particulate concentration measurement PM1.0, PM2.5; PM10 of the sensors compared to standard device Aerocet 531s.

PMS5003 and SPS30 sensors both had high precision, with the maximum deviations over the whole measuring range were below $31 \mu \mathrm{g} / \mathrm{m}^{3}$ and below 25 $\mu \mathrm{g} / \mathrm{m}^{3}$ respectively. Especially in the low particulate measuring ranges the standard deviation between the sensor values was below $10 \mu \mathrm{g} / \mathrm{m}^{3}$ (Table 3).

Low-precision sensors could cause dispersion of the obtained data, reducing sensor accuracy. The SM-UART-04L sensor has a rather high $60 \mu \mathrm{g} / \mathrm{m}^{3}$ deviation between sensors at all measured particulate ranges, which could make it very difficult to calibrate the sensor for practical use. 
Table 3. Table of results of standard deviation between sensors of the same type.

\begin{tabular}{cccc}
\hline \multirow{2}{*}{ Model } & \multicolumn{3}{c}{ Standard Deviation between sensors of the same type $\left(\mu \mathrm{g} / \mathrm{m}^{3}\right)$} \\
\cline { 2 - 4 } & PM1.0 & PM2.5 & PM10 \\
\hline PMS5003 & 9.50 & 17.00 & 31.00 \\
SPS30 & 23.13 & 25.00 & 12.00 \\
SM-UART-04L & 61.29 & 64.37 & 62.73 \\
\hline
\end{tabular}

As shown in Figure 3, the SM-UART-04L sensors had high precision at lower PM1.0 and PM2.5 concentrations $\left(<20 \mu \mathrm{g} / \mathrm{m}^{3}\right.$ for PM1.0 and $<50 \mu \mathrm{g} / \mathrm{m}^{3}$ for PM2.5); however, as the particulate concentration increased, the sensor precision got worse. This low precision could greatly affect the calibration process of sensor data since low precision results in large, nonlinear standard deviations which lead to complex calibration formula.

\section{3) Evaluate linear relationship of the sensor data}

The data obtained from all tested sensors had similar trending compared to the data from the Aerocet 531s reference equipment. Even with high particulate concentration (above $1000 \mu \mathrm{g} / \mathrm{m}^{3}$ ), the data obtained from the sensors was still linear compared to the data from the reference equipment. However, SM-UART-04L sensor was limited with its out-of-range output and therefore had poor linearity rating compared to other sensors.

As described in Figure 4, the results show that PMS5003 sensor had high linearity and high stability: $\mathrm{R}^{2}=0.89$ at particle size PM1.0; $\mathrm{R}^{2}=0.95$ in particle size PM2.5; $\mathrm{R}^{2}=0.87$ in particle size PM10. SPS30 sensor also had high linearity at particle size PM2.5 $\left(\mathrm{R}^{2}=0.95\right)$ and PM10 $\left(\mathrm{R}^{2}=0.99\right)$, but at particle size PM1.0, the linearity was quite low $\left(\mathrm{R}^{2}=0.56\right)$. SM-UART-04L sensor had high linearity at particle size PM1.0 $\left(\mathrm{R}^{2}=0.98\right)$, however, linearity at other particle sizes was very low with $\mathrm{R}^{2}<0.5$ (due to out-of-range problem).

4) Application of Calibration methods to improve sensor accuracy

a) Single-point calibration

Application of one-point calibration method in calibration of Plantower's DS- $\mathrm{CO}_{2}-20$ sensor

$\mathrm{CO}_{2}$ is a colorless, odorless, tasteless gas. It is the byproduct of breathing and burning of fossil fuels. Exposure to high concentrations of $\mathrm{CO}_{2}$ can have many negative health effects, such as headaches, dizziness, restlessness, shortness of breath, sweating, fatigue, increased heart rate, increased blood pressure, unconsciousness, asphyxiation, and convulsions.

The $\mathrm{CO}_{2}$ concentration measurement results using Plantower's DS- $\mathrm{CO}_{2}-20$ sensor (direct measurement using NDIR technology) were compared with the standard $\mathrm{CO}_{2}$ measuring device Testo 315-3. Figure 5 shows the measurement results without calibration.

As shown in Figure 5, the $\mathrm{CO}_{2}$ concentration measured by the DS- $\mathrm{CO}_{2}-20$ sensor was higher than that measured by the Testo 315-3; however, the deviation between the two measurements was "relatively" linear (the measured value of the 
PM1.0

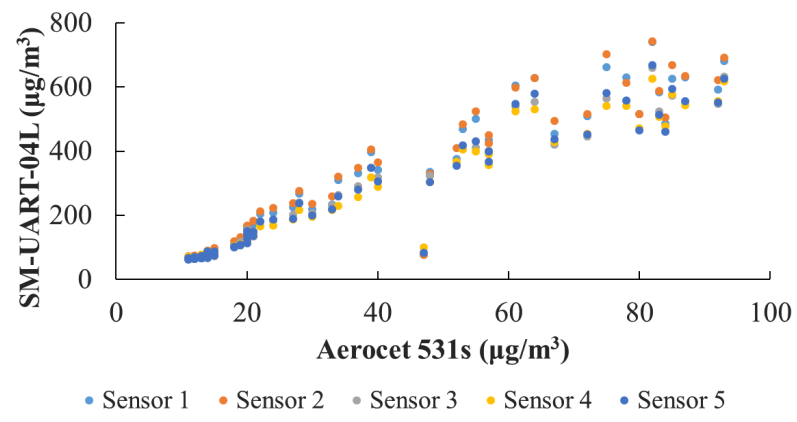

PM2.5

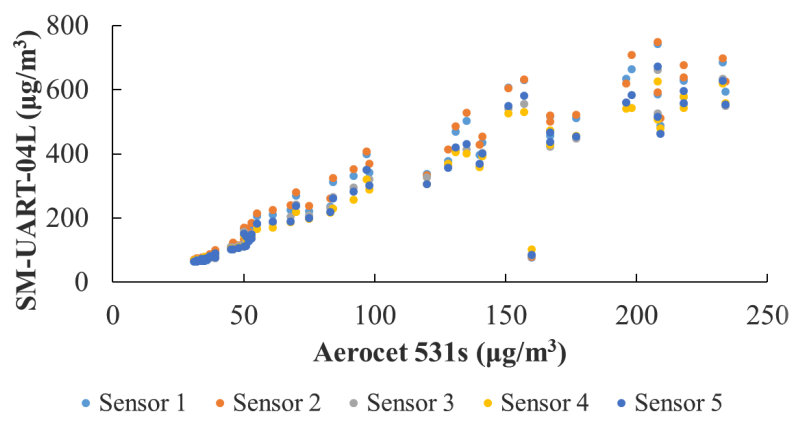

Figure 3. Results of analyzing the precision of sensor SM-UART-04L.

DS- $\mathrm{CO}_{2}-20$ sensor was about $300 \mathrm{ppm}$ higher than the standard measuring value), so the single point calibration method could be applied by subtracting the offset from the sensor measurement results, as shown in Figure 6.

The value measured with the DS- $\mathrm{CO}_{2}-20$ sensor after calibration and the Standard Testo 315-3 did not differ statistically ( $\mathrm{p}$-value $>0.05$ ).

b) Two-point calibration

Application of two-point calibration method in calibration of Plantower's PMS5003 sensor

PM2.5 particulate concentration measurement results using Plantower's PMS5003 sensor were compared with the standard measuring device Met One Aerocet 531. Figure 7 shows the measurement results before calibration.

As shown in Figure 7, the errors between PM2.5 concentrations measured by PMS5003 sensor and Met One Aerocet 531 were greater in high range (PM2.5 concentration $>500 \mu \mathrm{g} / \mathrm{m}^{3}$ ) compared to lower concentration (PM2.5 concentration $<200 \mu \mathrm{g} / \mathrm{m}^{3}$ ), so the one-point calibration method could not be applied to calibrate the sensor as with the $\mathrm{CO}_{2}$ sensor above. Instead, it is necessary to use the two-point correction method as shown in Figure 8.

The difference between values measured with the PMS5003 sensor (calibrated) and the Aerocet 531s device was reduced but still statistically different (p-value <0.05).

c) Multi-point curve calibration

Application of multi-point curve calibration method in calibration of PMS5003 sensor 
PM1.0

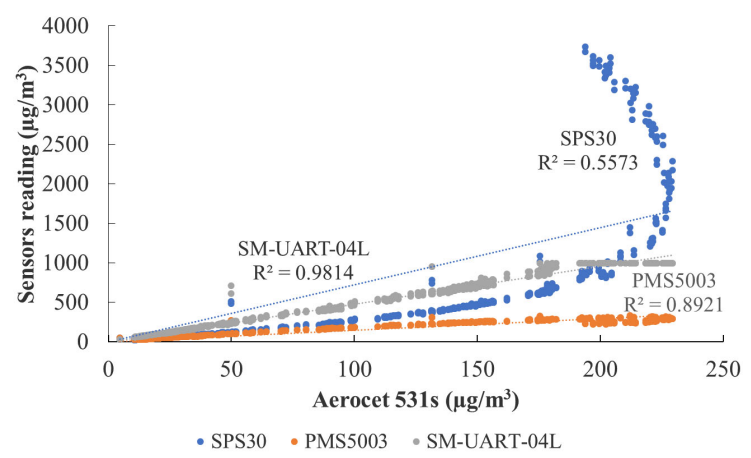

PM2.5

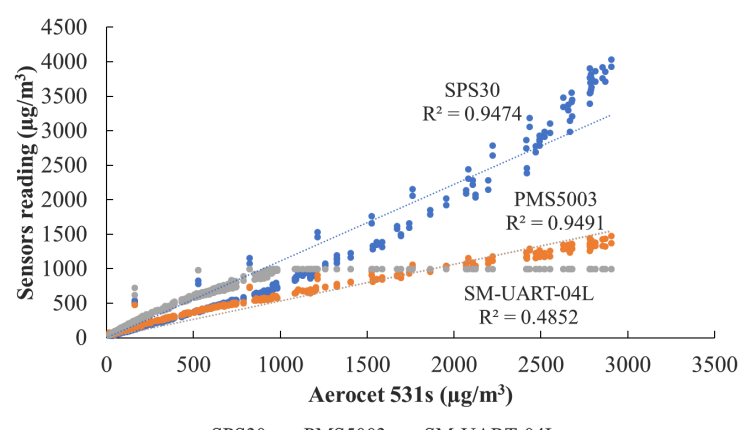

-SPS30 • PMS5003 • SM-UART-04L

PM10

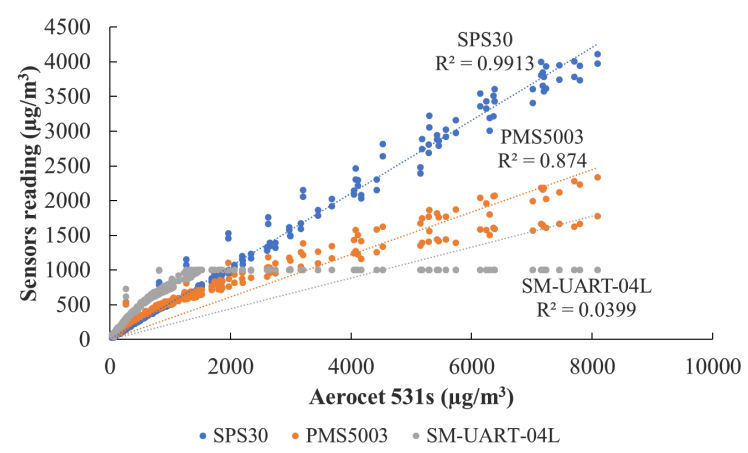

Figure 4. Analysis chart of linearity between sensors and reference device data.

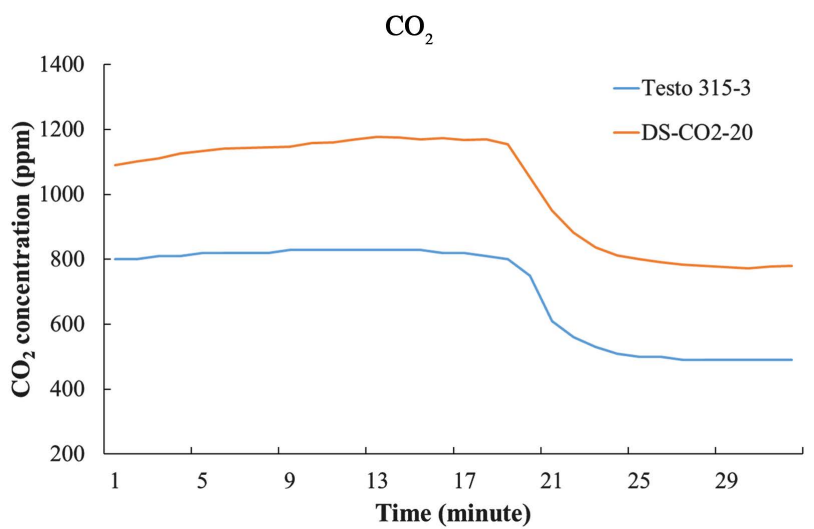

Figure 5. $\mathrm{CO}_{2}$ concentration measured with a DS- $\mathrm{CO}_{2}-20$ sensor and a standard Testo 315-3 meter. 
$\mathrm{CO}_{2}$

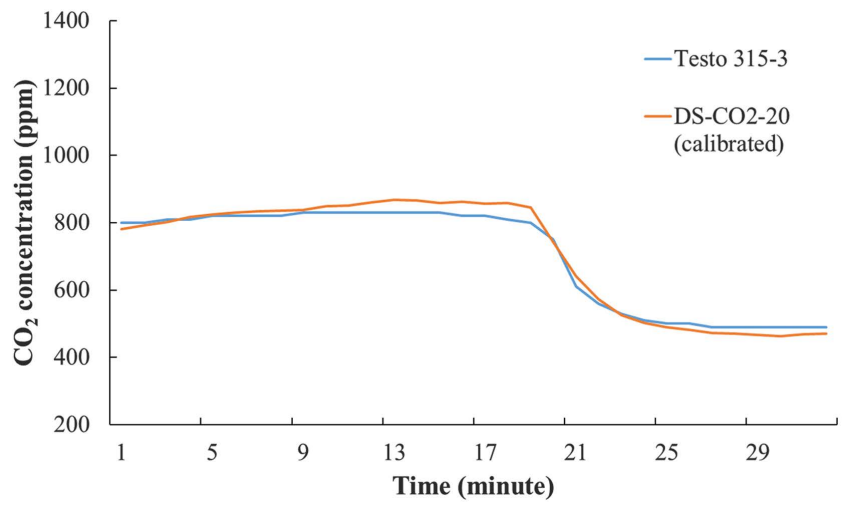

Figure 6. $\mathrm{CO}_{2}$ concentration measured with the $\mathrm{DS}-\mathrm{CO}_{2}-20$ sensor after calibration and the standard tester Testo 315-3.

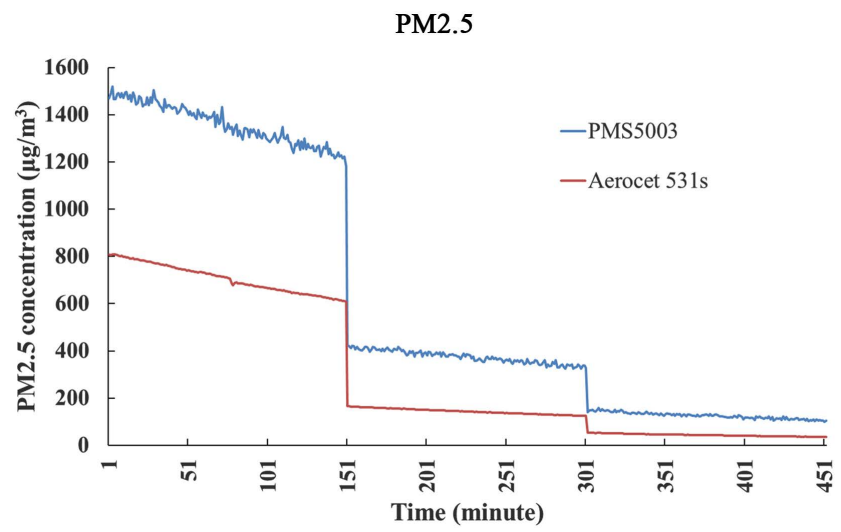

Figure 7. PM2.5 particulate concentration measured by PMS5003 sensor and Met One Aerocet 531 standard meter.

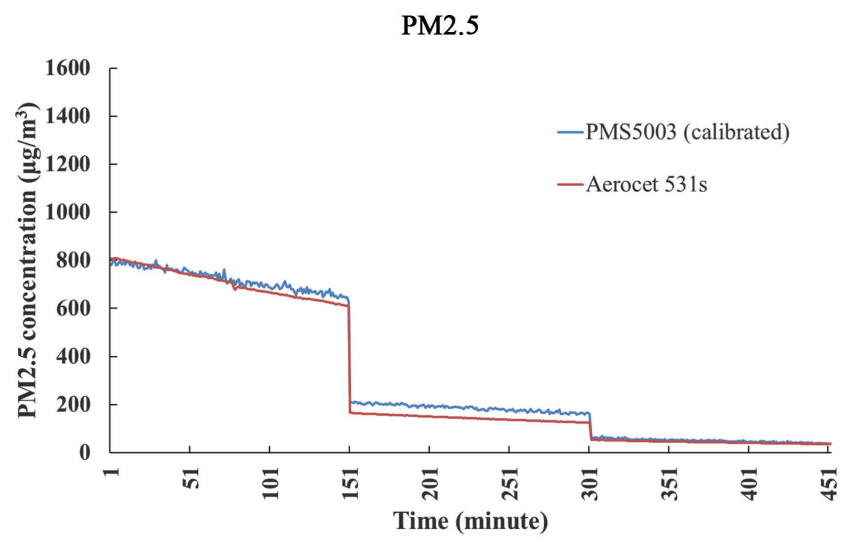

Figure 8. PM2.5 concentration measured with PMS5003 sensor (calibrated by two-point calibration method) and Met One Aerocet 531 standard meter.

As shown in Figure 8, although the calibrated values of the PMS5003 sensor were quite close (fitted) to that of the standard device, there was still a relatively large error in the dust range $200-700 \mu \mathrm{g} / \mathrm{m}^{3}$. In this case, it would be necessary to use the multi-point curve method for sensor calibration. Figure 9 shows the 
corrected sensor value using one of the most common regression functions, the polynomial function (the data below uses the second degree polynomial function, $y=A+B x+C x^{2}+D x^{3}$ where $\mathrm{x}$ denoted the measured value with the PMS5003 sensor and y was the measured value of the standard measuring device).

As shown in Figure 9, the calibrated sensor values using the multi-point curve method were more fitted with standard measuring device value than the two-point calibration method (Figure 8). The difference between values measured with the PMS5003 sensor (calibrated) and the Aerocet 531s device was statistically different ( $\mathrm{p}$-value $>0.05$ ).

We then validated the multi-point curve method by applying it to another set of data. Figure 10 illustrated PM2.5 data from four PMS5003 sensors after calibration compared to Aerocet 531s device.

Values measured with the all four PMS5003 sensors (after calibration) and the Met One Aerocet 531 standard meter were not statistically different ( $\mathrm{p}$-value > $0.05)$.

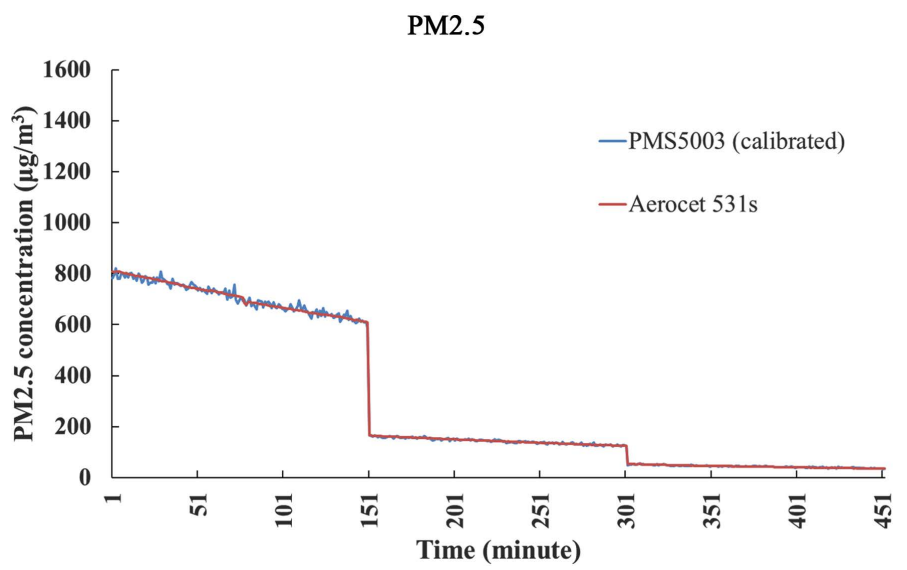

Figure 9. PM2.5 concentration measured by PMS5003 sensor (calibrated using the multi-point curve method) and Met One Aerocet 531s standard device.

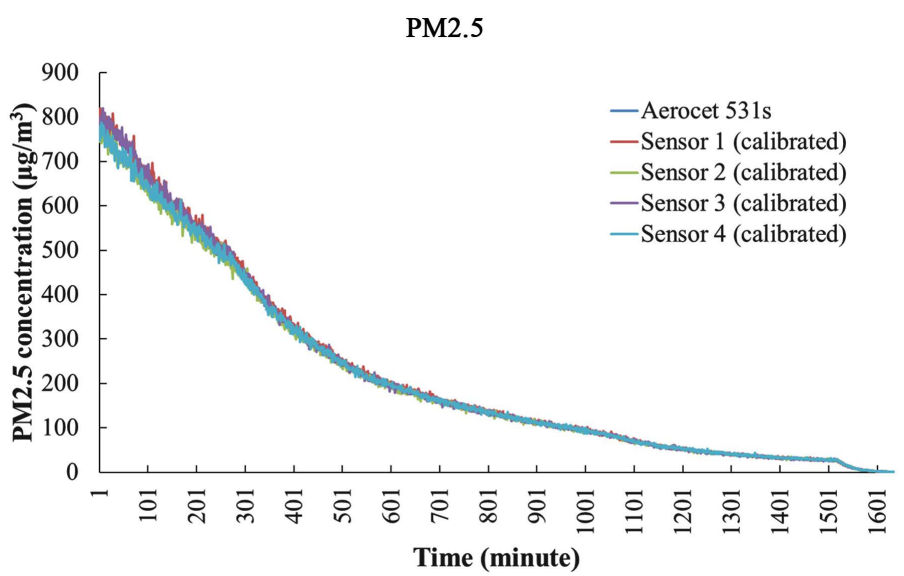

Figure 10. PM2.5 concentration measured by PMS5003 sensors (after calibration) compared with Aerocet 531s standard device. 


\section{Conclusions}

Factors affecting sensor accuracy and precision like temperature and relative humidity conditions will need to be further tested to fully cover the whole range of sensor measurement. All the tests performed in this study were kept within the range of temperature of $15^{\circ} \mathrm{C}-30^{\circ} \mathrm{C}$ and relative humidity of $50 \%-85 \%$. Extreme conditions such as very cold/high temperature and/or relative humidity may seriously reduce sensor accuracy.

Nevertheless, the development of low-cost sensor technologies has unlocked opportunities for affordable air quality monitoring devices. In fact, a lot of air purifiers and personal air quality monitoring devices in the market have already integrated these sensors in their designs. Being combined with the calibration process will help to ensure the sensor's accuracy equivalent to that of standard equipment. In this article we have evaluated several low-cost sensor regarding their accuracy and precision as well as presented a few calibration methods to calibrate those sensors. The one-point and two-point calibration methods are highly effective when the sensor errors are relatively linear with the standard measuring device. However, when the error between the sensor and the standard instrument is not linear, it is necessary to use the multi-point curve method to adjust the measurement results of the sensor.

\section{Acknowledgements}

The authors wish to acknowledge the collaboration of our colleagues Diem T. Lam and Thanh T. Nguyen for their helps in carrying out the particulate measurement.

\section{Conflicts of Interest}

The authors declare no conflicts of interest regarding the publication of this paper.

\section{References}

[1] World Health Organization (Accessed on 11/15/2020). https://www.who.int/news-room/detail/02-05-2018-9-out-of-10-people-worldwidebreathe-polluted-air-but-more-countries-are-taking-action

[2] World Health Organization (Accessed on 11/15/2020). https://www.who.int/news-room/spotlight/how-air-pollution-is-destroying-our-hea lth

[3] Manisalidis, I., Stavropoulou, E., Agathangelos, S. and Bezirtzoglou, E. (2020) Environmental and Health Impacts of Air Pollution: A Review. Frontiers in Public Health, 8, Article 14. https://doi.org/10.3389/fpubh.2020.00014

[4] Kelly, F.J. and Julia C.F. (2015) Air Pollution and Public Health: Emerging Hazards and Improved Understanding of Risk. Environmental Geochemistry and Health, 37, 631-649. https://doi.org/10.1007/s10653-015-9720-1

[5] Duan, R.-R., Hao, K. and Yang, T. (2020) Air Pollution and Chronic Obstructive Pulmonary Disease. Chronic Diseases and Translational Medicine, 6, 260-269. 
https://doi.org/10.1016/j.cdtm.2020.05.004

[6] Isabella, A.-M. (2019) Air Pollution and Chronic Obstructive Pulmonary Disease Exacerbations: When Prevention Becomes Feasible. American Journal of Respiratory and Critical Care Medicine, 199, 547-563. https://doi.org/10.1164/rccm.201810-1829ED

[7] El Morabet, R. (2019) Effects of Outdoor Air Pollution on Human Health. Reference Module in Earth Systems and Environmental Sciences. https://doi.org/10.1016/B978-0-12-409548-9.11012-7

[8] Gary, F. (2019) The Invisible Killer: The Rising Global Threat of Air Pollution-and How We Can Fight Back. Melville House, London.

[9] Schmidt-Ott, A. and Ristovski, Z.D. (2003) Measurement of Airborne Particles. In: Morawska, L. and Salthammer, T., Indoor Environment: Airborne Particles and Settled Dust, Wiley-VCH Verlag GmbH \& Co KGaA, Weinheim, 56-81. https://doi.org/10.1002/9783527610013.ch2b

[10] United States Environmental Protection Agency (Accessed on 11/15/2020). https://www.epa.gov/pm-pollution/health-and-environmental-effects-particulate-m atter-pm

[11] World Health Organization (Accessed on 11/15/2020). https://www.euro.who.int/_data/assets/pdf_file/0006/189051/Health-effects-of-par ticulate-matter-final-Eng.pdf?ua=1

[12] Noble, C.A., Vanderpool, R.W., Peters, T.M., McElroy, F.F., Gemmill, D.B. and Wiener, R.W. (2001) Federal Reference and Equivalent Methods for Measuring Fine Particulate Matter. Aerosol Science \& Technology, 34, 457-464.

https://doi.org/10.1080/02786820121582

[13] The Environmental Protection Agency (Accessed on 01/12/2021). https://www3.epa.gov/ttn/amtic/files/ambient/pm25/spec/drispec.pdf

[14] Chung, A., Chang, D.P.Y., Kleeman, M.J., Perry, K.D., Cahill, T.A. Dutcher, D., McDougall, E.M. and Stroud, K. (2001) Comparison of Real-Time Instruments Used to Monitor Airborne Particulate Matter. Journal of the Air \& Waste Management Association, 51, 109-120. https://doi.org/10.1080/10473289.2001.10464254

[15] Peters, T.M., Norris, G.A., Vanderpool, R.W., Gemmill, D.B., Wiener, R.W., Murdoch, R.W., Mcelroy, F.F. and Pitchford, M. (2001) Field performance of $\mathrm{PM}_{2.5}$ Federal Reference Method Samplers. Aerosol Science \& Technology, 34, 433-443. https://doi.org/10.1080/02786820116873

[16] The New South Wales Department of Planning, Industry and Environment (Accessed on 12/05/2020).

https://www.environment.nsw.gov.au/topics/air/understanding-air-quality-data/glo ssary-of-air-quality-terms

[17] Adafruit Industries (Accessed on 12/05/2020). https://cdn-learn.adafruit.com/downloads/pdf/pm25-air-quality-sensor.pdf

[18] Mouser Electronics (Accessed on 12/05/2020). https://www.mouser.com/catalog/specsheets/Amphenol_12202018_AAS-916-139ATelaire-SM-UART04L-AppNote-102018-web.pdf

[19] Sensirion AG (Accessed on 16/03/2021). https://www.sensirion.com/fileadmin/user_upload/customers/sensirion/Dokument e/9.6_Particulate_Matter/Datasheets/Sensirion_PM_Sensors_Datasheet_SPS30.pdf

[20] Amaral, S.S., de Carvalho Jr., J.A., Costa, M.A.M. and Pinheiro, C. (2015) An Overview of Particulate Matter Measurement Instruments. Atmosphere, 6, 1327-1345. 
https://doi.org/10.3390/atmos6091327

[21] American Cleanroom Systems (Accessed on 12/05/2020). https://www.americancleanrooms.com/cleanroom-classifications/

[22] Alastair, L. and Edwards, P. (2016) Validate Personal Air-Pollution Sensors. Nature, 535, 29-31. https://doi.org/10.1038/535029a

[23] Morawska, L., Thai P.K., et al. (2018) Applications of Low-Cost Sensing Technologies for Air Quality Monitoring and Exposure Assessment: How Far Have They Gone? Environment International, 116, 286-299.

https://doi.org/10.1016/j.envint.2018.04.018

[24] Electronics Projects Focus (Accessed on 12/05/2020). https://www.elprocus.com/sensor-calibration-definition-and-its-application/

[25] Adesto (Accessed on 11/05/2020). https://www.adestotech.com/wp-content/uploads/SmartEdge-Platform-CalibrationWhite-Paper-Final-Nov18.pdf

[26] Adafruit Industries (Accessed on 12/05/2020). https://cdn-learn.adafruit.com/downloads/pdf/calibrating-sensors.pdf 